\title{
Institución, infancia y subjetividad
}

Cinthya Berenice Rodríguez Piedraํํㄹ y María del Carmen Manzo

Chávez ${ }^{1}$

\section{Resumen}

Se presenta un ensayo a partir de una experiencia de trabajo del cuerpo académico de Estudios sobre la infancia y la adolescencia de la Facultad de Psicología de la Universidad Michoacana de San Nicolás de Hidalgo titulada "Programa de diagnóstico e intervención para la adopción" realizada en DIF Michoacán en 2016-17 con niños y adolescentes de una institución llamada "Casa hogar". Tomando un posicionamiento crítico desde un paradigma psicoanalítico, se desarrolla una serie de reflexiones en torno al impacto del discurso institucional en el desarrollo del niño como línea de trascendencia para la subjetivación, constituida a partir de la mirada del otro. Se discute la manera en

1 Universidad Michoacana de San Nicolás de Hidalgo, cindybererp@gmail.com 
que el discurso institucional causa efecto en el niño al significarlo como niño abandonado; nombrarlo y enunciarlo como sujeto de carencia y merecedor de caridad, posicionándolo en ese lugar subjetivo, en ocasiones inamovible, por ser la institución la que decide siempre por él en nombre de su cuidado y de su bien.

Palabras clave: institución; infancia; orfandad; subjetividad.

\section{Abstract}

This essay is based on a work experience conducted by the research group on Studies on childhood and adolescence at the Faculty of Psychology of the Universidad Michoacana de San Nicolás de Hidalgo, entitled "Program of diagnosis and intervention for adoption" held at DIF Michoacán in 2016-17 with children and adolescents from an institution called "Casa Hogar". Taking a critical position based on a psychoanalytic view, a series of reflections on the impact of the institutional discourse over the development of the child as a line of transcendence for subjectification since it is constituted from the others' gaze. The way in which the institutional discourse causes an effect on the child is discussed, since it defines him or her as an abandoned child when naming him and enunciating him as a subject in need and deserving of charity; positioning him in that subjective 
place, sometimes immovable, because it is an institution that always decides for him in the name of his care and his good.

Keywords: institution; childhood; orphanhood; subjectivity.

El presente ensayo se realizó a partir del contacto y el trabajo realizado en casas hogar del DIF Michoacán durante cuatro años. En un primer momento, dicho trabajo se realizó con la intención de incidir en la prevención de conductas criminales y antisociales de las niñas de casa hogar. En un segundo momento, ya dentro del programa de adopción, se trabajó con la finalidad de intentar desmontar los saberes y procedimientos que mostraban su ineficiencia evidente o, en su defecto, operar desde lógicas más favorables para los menores institucionalizados. Es en este proceso que se nos plantea el escenario de lo que la institución ofrece al psiquismo de los menores.

Si bien es cierto, que las instituciones siempre fallan y esa falla permite la inserción de otras miradas, de otros paradigmas y de otras posibilidades para los niños, niñas y adolescentes, ella también produce resistencia y rigidez en su estructura, protegiendo más los objetivos institucionales que los singulares de los niños. Lacan dice que "todo verdadero significante es, en tanto tal, un significante que no significa nada" (1956, p. 264). El significante, es aquello que "no 
significa nada". Y en tanto que no significa nada, "es capaz de dar en cualquier momento significaciones diversas" (1956, p. 271).

A partir de la mirada que lo significa como niño abandonado, lo nombra y lo enuncia como sujeto de carencia, y merecedor de caridad es que se construye el niño en la institución. El discurso institucional causa un efecto en él y lo posiciona en cierto lugar, en ocasiones inamovible, en tanto que es dicha institución la que decide qué será de él, siempre decide por él en nombre de su cuidado. Este escrito plantea un abordaje de la institución y de los efectos que produce en la subjetivación de los niños específicamente de casa Hogar, DIF Michoacán, desde una mirada psicoanalítica.

El discurso institucional transgrede la potencialidad del sujeto, y lo captura en algo que es (niño abandonado, huérfano, entre otros) limitando la posibilidad de ser otra cosa que no sea objeto de caridad. Sin posibilidad de enunciarse como sujetos, de enunciar sus propias palabras, dado que estas giran en torno a ¿dónde están mis papás?, ¿por qué no tengo familia?, ¿cuándo van a venir por mi?, preguntas para las cuales no hay respuesta más honesta que decir quizá "no lo sé", la postura de la institución es, sin embargo, que siempre sabe, sabe lo que es bueno para ellos, está situada como gran Otro autorizado para decidir el futuro de los menores, el cual sin duda alguna no es prometedor. Muchos de ellos al cumplir 18 años y perder la protección del Estado, considerados ya como 
adultos de la noche a la mañana y, por eso, con capacidad de decidir, caen en el crimen, en las calles, en las drogas y no dejan de ser nunca los desvalidos que la institución se dedicó a construir durante su estancia en ella.

\section{Instituciones}

Es interesante plantear la investigación sobre el origen de las instituciones. $Y$ es que podemos reflexionar acerca de si la institución sostiene la vida humana o si la vida humana sostiene a las instituciones.

En Engels podemos encontrar una forma de problematizar lo anterior. En su texto El origen de la familia, propiedad privada y el Estado, ubica dos momentos prehistóricos de la cultura que son el salvajismo y la barbarie, los cuales se encuentran caracterizados por la ausencia de la institución. Se puede cuestionar si en esta época de prehistoria, en donde el sujeto es aún salvaje, hay humanidad como tal, es decir, hay vida humana, a un nivel primitivo, instintivo. Así, en un periodo posterior, se encuentra la civilización y con ella la aparición de la primera institución reconocida y vigente hasta ahora: la familia. Con ella, la propiedad privada y el Estado como regulador. A la par de la civilización, hay un precio a pagar: la esclavitud.

En su origen, la palabra familia no significa la idea, mezcla de sentimentalismo y de disenciones domés- 
tica, del filisteo de nuestra época; al principio, entre los romanos, ni siquiera se aplica a la pareja conyugal y a sus hijos, sino tan sólo a los esclavos. Famulusquiere decir esclavo doméstico y familia es el conjunto de esclavos pertenecientes a un mismo hombre. En tiempos de Gayo la familia, id es patrimonium (es decir, herencia), se transmitía aún por testamento. Esta expresión la inventaron los romanos para designar un nuevo organismo social, cuyo jefe tenía bajo su poder a la mujer, a los hijos y a cierto número d esclavos con la patria potestad romana y el derecho de vida y muerte sobre todos ellos (Engels, 2017, p. 22).

La relación a condición en una institución es de esclavitud, un esclavo que le pertenece a un amo. Esta dialéctica de la que habla Hegel se encuentra presente en las formas de existencia de modo imperante $e$ inamovible:

Para que la realidad humana pueda constituirse en tanto que realidad "reconocida" hace falta que ambos adversarios queden con vida después de la lucha. Más eso sólo es posible a condición de que ellos adopten comportamientos opuestos en esa lucha. Por actos de libertad irreductibles, es decir, imprevisibles o "fortuitos", deben constituirse en tanto que desiguales en y por esa misma lucha. Uno de ellos, sin estar de ningún modo "predestinado", debe tener miedo del otro, debe ceder al otro, debe negar el riesgo de su vida con miras a la satisfacción de su Deseo de "reconocimiento". Debe abandonar su deseo y satisfacer el 
deseo del otro: debe "reconocerlo" sin ser "reconocido" por él. Pero, "reconocer" así implica "reconocerlo" como Amo y reconocerse y hacerse reconocer como Esclavo del Amo (Kojève, 1982 p.5).

En términos psicoanalíticos, el gran Otro haría las funciones del Amo, función que encarna la institución. Es así que la organización institucional nombra un padre que es la máxima autoridad, el director, el rector, el presidente, que al estar en ese lugar se configura como el Amo, dueño de todos los ahí involucrados, dictador de voluntades y de actos, que decidirá lo que el otro debe hacer/ser, por supuesto por su bien.

El mandato principal de las instituciones es imponer normas, marcar límites, vigilar y si es necesario castigar el incumplimiento. Foucault, en su texto Vigilar y Castigar (1975/1976), plantea claramente el enfoque disciplinario, de vigilancia y de castigo que impera en las instituciones, el nacimiento de la prisión. La segregación en sectores de buenos y malos, normales y anormales, es una clasificación que permite legalizar la relación esclavo y amo. Si bien es cierto, más allá de la familia, las instituciones que atañen este trabajo son del orden de lo social, basta pensar en los psiquiátricos, en las cárceles, fabricas e incluso en las escuelas, así como en las casas hogar o de asistencia social, todas ellas con sistemas de privación de libertad, aunque en algunas de ellas esto ocurra a tiempo parcial. La lógica en la mayoría es el uso de uniforme, para ser identificados como pertenecientes a 
tal o cual institución y registrar ingresos y salidas. Para poder vigilar en dónde se encuentran, ahora se han sumado los sistemas de seguridad de cámaras que no son sino una mejora del panóptico. Estas formas de dominación y de control se sostienen en la premisa del conocimiento. "Son los que saben" qué es bueno para nosotros, dispositivos de biopoder para enseñarnos como vivir una buena vida, lo que sea que eso signifique.

Bajo el argumento del conocimiento, la institu-ción siempre sabe, y por lo tanto siempre puede-o quizá porque tiene poder es entonces que sabe-sabe lo que es bueno para el otro, para el usuario, para el paciente y decide en consecuencia. La instituciona-lización se entiende entonces como los efectos que hay en un sujeto e incluso en un objeto de la institución. Así, pensar en los niños de casa hogar nos permite reflexionar sobre cuáles pueden ser los efectos o los estragos que la institución tiene en ellos.

\section{Infancia}

Hay diversos autores que teorizan sobre la infancia, la explican desde su desarrollo tanto psicogenéticoPiaget-como psicosexual-Freud (1905/2008). Así bien, las teorizaciones que surgen son un intento de enunciar algo respecto a lo que en el menor ocurre. La postura del menor como un fetiche para la sociedad ha ido cada vez en aumento, quizá porque el Estado los 
ubica como sujetos incapaces de hablar, o de hacerse cargos de sí mismos.

¿Qué se entiende por infancia? El "término proviene de la palabra latina infant, que significa el mudo, que no habla, de ahí el término infancia, infatiaae incapaz de hablar" (López, 2014, p.85). Llama la atención dicha definición en tanto que si el ser humano es el único de las especies vivas en el planeta que habla, que el menor sea concebido como el que no habla implica quizá una deshumanización del mismo. Así, no sería extraño observar que algunos niños se comportan incluso como "animalitos", por lo menos tal como lo expresan algunos de los cuidadores, o que otros se releguen como si fueran objetos sin importancia. Sin embargo, tenemos a aquellos que gritan y gritan fuerte al adulto, tal vez para decirle que ellos sí hablan, y que son humanos, pero esto es tomado como algo a corregir, no a escuchar. Cuando nos presentan la demanda de atención, ella se enuncia en términos de eliminar esas conductas desagradables que vuelven el día a día algo tedioso para la institución: hay que corregir y eliminar las "malas" conductas; hay que hacerlos buenos niños.

El ser humano es también la única especie viva del planeta que necesita de otro para su supervivencia, tanto por su cuerpo biológico como por el cuerpo pulsional. La existencia objetiva del cuerpo biológico pareciera alcanzar mayor importancia que la del psíquico en, por ejemplo, la desnutrición, que se hace 
evidente. Así, habrá que velar por que el niño haga sus tres comidas al día, pero los afectos, que se juegan en lo psíquico aunque se manifiestan de muchas formas, no son tan visibles ni tan escuchados. Entonces se escucharan frases como "no tiene a su mamá, pero por lo menos tiene techo y comida". Lo cierto es que se tiene que escuchar con igual prioridad lo psíquico y escuchar lo que el sujeto dice de distintas formas, el lenguaje por el que se enuncia. El niño buscará enunciarse de todas las formas; hacerse un ser, aunque sus formas escapen a nuestra comprensión. Habría que permitir esas formas y no sofocarlas sólo porque nos parezcan incómodas o molestas. La anulación de su discurso puede ser traducida en la anulación de su ser. Pero eso que puede surgir en su decir es, sin embargo, callado por la institución porque él no entiende o no sabe lo que quiere, lo que le conviene o lo que ocurre. Dolto dirá al respecto de la inteligencia de los niños:

Un bebé es más inteligente de lo que se cree. O sea, que cada uno de nosotros, cuando era bebé, era bastante más inteligente de lo que es ahora, de adulto. (Risas). Entiende totalmente el lenguaje cuando alguien le habla para comunicarle algo sobre lo cual puede tener percepciones, cuando alguien le dice con palabras lo que ya está viviendo o experimentando.

Algunos psicoanalistas les cuesta admitir que se puede hablar a un bebé inmediatamente, desde su 
nacimiento. Sin embargo, son precisamente las primeras cosas oídas las que marcan toda su vida y permanecen indelebles sobre la banda magnética de su memoria (1985/2006, p. 90).

Los discursos que hay alrededor de los menores parten de la lógica institucional, no desde el padecer del aque-jado. Si la institución es el amo, el niño será el esclavo de ésta, y por ende el débil, el abandonado, el pobrecito, el tonto, el hiperactivo, incluso el loco.

Aproximaciones terapéuticas producidas por el propio discurso institucional, básicamente, programas de preven-ción, de apego al tratamiento, o de psicoeducación; prácticas que tienen en común la búsqueda de los propósitos propiamente institucionales y un bienestar del sujeto pensado desde la institución, no desde el aquejado, con lo cual se deja de lado el carácter singular del sufrimiento de quienes son atendidos en las instituciones (Rojas, Ribeiro y Novoa, 2015 p. 91).

\section{Subjetividad}

La Real Academia Española (2018) define subjetividad como "adj. Perteneciente o relativo al sujeto, considerado en oposición al mundo externo". Podemos entonces entenderlo como aquello que es propio, lo que le da singularidad al sujeto, lo que es suyo.

La desubjetivación en las instituciones es quizá el principal objetivo o demanda de las mismas, dado que 
el funcionamiento corresponde al sistema disciplinario y de control, lo que les permite una organización sistemática y funcional. El sistema y lo humano corresponden a polaridades en su funciona-miento. Mientras en el sistema institucional rigen la rigidez, las estadísticas, la homogenización, la fechas de caducidad y lo objetivo, en lo humano se ponen de relieve la singularidad, la heterogeneidad, la flexibilidad, y los tiempos de cada sujeto. Son mundos inconmensurables; son, a priori, imposibles de ensamblar. Sin embargo, la insistencia en someter uno al otro se hace bajo la premisa de ayudar: la institución ayuda a los sujetos, aunque los estragos sean en ocasiones mayores que los beneficios; aunque ignorar la exigencia de la subjetivación sea el precio que se cobra cada institución.

Si bien, las intenciones de la institución al parecer siempre son buenas, la rigidez plantea el apegarse a las normas y reglas que establece, justificadas en el bienestar de todos. Es cierto que las reglas y las normas posibilitan cierto nivel de funcionamiento. Sin embargo, la rigidez en su cumplimiento violenta la subjetividad de quienes deben adherirse a ellas. Pensemos en el siguiente ejemplo respecto al acto de asesinar. La pregunta sería "¿agredir es malo?". La respuesta inmediata es "sí". Por lo tanto, la institución castigará al agresor. Lo siguiente es preguntar “¿agredir en defensa propia es malo?”. La institución centrará la respuesta en el acto y no en la causa. Por lo 
tanto, agredir es malo aun siendo en defensa propia, es decir que en esta situación el acto de agredir a alguien nos convierte en criminales, y aunque se pueda plantear cierta negociación respecto a la condena, el resultado es ir a prisión. En la subjetividad, uno podría discutir si agredir en defensa propia, o robar comida, o dinero, corresponden a un delito sin nada más que discutir.

Así pues, la institución garantiza su existencia a partir del cumplimento del marco que la regula. Ingresar en una institución demanda seguir la consigna de "ponerte la camiseta" situarse del lado de la institución más que del lado de lo singular. Por ello, la desubjetivación deja pocas posibilidades de surgir como ser único e irrepetible. Cuando el sujeto es habitado e invadido por la institución, tiene escasas posibilidades de emerger él mismo. Para dar cuenta de esto, habría que escuchar el malestar de lo humano en la actualidad, un malestar vinculado con la pertenencia a las instituciones. Entre los síntomas se encuentran el cansancio de una economía que requiere tener dos trabajos y aún así no ganar lo suficiente; la depresión, la excesiva ocupación laboral, la demanda de siempre estar haciendo algo, trabajar horas extras e incluso los fines de semana para ser los seres exitosos que el gran Otro exige. Las horas que se invierten al servicio de la institución son muchas más de las que se invierte en el ser mismo. 
Estar atravesado por la institución deja secuelas de trascendencia para el sujeto, sobre todo en la etapa infantil y adolescente, ya que son momentos de estructuración psíquica, y las posibilidades de defender una singularidad que está surgiendo y conformándose, son pocas. Si bien como adulto uno puede enunciar su ser y sus formas de estar en la institución teniendo como opción el retirarse de dicho escenario, el menor es vestido por la "camiseta" sin tener oportunidad de quitársela. No es que él no pueda enunciarse, defenderse o resistirse a tal alienación, sino que es cobijado por la institución y legalmente la opinión de éste no es escuchada. Lo será hasta que tenga 18 años.

Habrá que pensar y reflexionar sobre los sujetos que surgirán y sobre los actos o pensamientos que puedan tener a partir de una subjetividad llena de institución que corresponde a discursos como "tú no sabes lo que quieres", "eres un niño, ya de grande entenderás", una forma de decirles que no tienen la capacidad de entender asumiendo la infancia como cierta incapacidad mental. "Es por tu bien", "obedece", "no preguntes eso", "cállate", y situaciones como "hay que llevar a los niños a tal evento de caridad", "llevarlos a que le canten al papa", "pobrecitos", "hay que darles caridad". 


\section{Conclusiones}

La escucha como dispositivo de subjetivación no es una propuesta nueva. Freud edifica el psicoanálisis en la tesis de que la palabra es la cura. Eso nos puede llevar a emerger de nuestro propio deseo y ser singulares. El gran Otro en la posmodernidad ha perfeccionado con y en las instituciones los dispositivos de control, estableciendo quién puede hablar y quién no. Los sujetos que tienen la autorización de hablar socialmente son los que se encuentran en el sector productivo y de consumo; son ellos los que pueden hablar y ser escuchados por un otro, aunque vacío como en el caso de las redes sociales, son los que producen y son activos en el sector económico, que podrán comprar un iphone. Son ellos los que nos venden el tiempo con el que podemos hablar y muy amablemente nos dan minutos gratis que nunca agotamos por no tener tiempo dado que estamos produciendo. Sólo hablan los que son activos socialmente.

La población que no entra en ese sector de la producción es relegada. El anciano se manda a un asilo, el loco se interna en un psiquiátrico, el criminal es llevado a la cárcel y el niño huérfano o abandonado es llevado a una casa hogar. Cuando está en edad productiva, sale. Si bien el objetivo de la casa hogar es insertar a los huérfanos en lo social como seres productivos porque con eso ha cumplido su cometido, parece ser que ellos sólo cambian de institución pero 
no de lugar. Fueron muy bien capturados en ciertos significantes: pobrecitos, desvalidos, débiles, objetos de caridad; de esa forma seguirán su vida adulta y eso los hará regresar a una de las instituciones de encierro, porque es ahí donde pueden ser lo que les enseñaron ser.

Las instituciones funcionan bien; los que no estamos funcionando bien somos nosotros, los sujetos institucionalizados, sucumbiendo sin ningún tipo de resistencia crítica e incluso sin ningún acto revolucionario, tomando como dogma lo dictado en el marco de la lógica institucional. En ese caso, habrá que reflexionar si nuestras subjetividades son realmente nuestras o de dónde vienen.

Así, el adulto cuenta con una oportunidad de decir, pero los niños no alcanzan ni siquiera a escucharse. Su reducción a objeto del Estado es violenta y evidente. Pero quienes son la institución-de algún modo somos nosotros mismos-al ponerse la camiseta, resultan alienados. La alienación produce el engaño de ser los amos de esclavos, siempre se prefiere ser el amo, pero habrá que pensarnos como semejantes, en tanto que ese discurso quiere hacernos creer que también somos amos, pero si se tiene amo por consiguiente uno es esclavo.

La relación del psicoanálisis con la universidad es siempre tensa pero aparece aunque sea como ese saber no deseado por la universidad pero necesario en tanto que dice algo del sujeto. Las disciplinas siempre 
buscarán saber más sobre el ser humano, es decir, el ser humano siempre busca saber sobre el mismo quizá con la ilusión de algún día comprenderse. En otras instituciones, esta relación es casi nula, puesto que las instituciones de encierro priorizan la estadística, la velocidad de los tratamientos, lo rentable en todos los términos-sobre todo económicos. Quieren algo rápido que no cueste tanto dinero. Es por eso que es un reto entrar a dichos dispositivos de control y vigilancia resistiendo la alienación voraz imperante, e intentando desmontar esos discursos de desubjetivación o de transgresión, la repetición arraigada de eso que dicen no quieren, si es que lo que quieren es curar al internado. Uno no siempre sale bien librado de eso, pero se podrán buscar formas de tocar esos dispositivos aunque sea con un escrito.

\section{Referencias}

Dolto, F. (1985/2006). Niños Abandonados. El

Seudodébil. En Seminario de psicoanálisis de niños 2 (págs. 89-99). México: Siglo XXI.

Freud, S. (1905/2008). La sexualidad infantil. En Tres ensayos de teoría sexual (págs. 87-125). Buenos Aires: Amorrortu.

Foucault, M. (1975/1976). Vigilar y Castigar. El nacimiento de la prisión. México: Siglo XXI. Kojève, A. (1982). La dialéctica del amo y del esclavo en Hegel. Buenos Aires, La Pléyade. 
Lacan, J. (1956/2008). Seminario 3. La Psicosis.

Buenos Aires: Paidós.

López, A. (2014) Cómo hablan los niños. En A. Colín

(Coord.), El niño y el discurso del Otro (págs. 85108). México: Kanankil.

Rojas, M., Ribeiro, R. y Novoa, V. (2011). Apuntes sobre la atención clínica en Instituciones. En R. De La Mora y R. Ribeiro (Coords.), Psicoanálisis, clínica y sociedad (págs. 91-110). México:

Fontamara. 


\section{(c) (1) (3)}

\section{Esta obra está bajo una \\ Licencia Creative Commons Atribución-NoComercial- Compartirlgual 4.0 Internacional}

Usted es libre de compartir o adaptar el material en cualquier medio o formato bajo las condiciones siguientes: (a) debe reconocer adecuadamente la autoría, proporcionar un enlace a la licencia e indicar si se han realizado cambios; (b) no puede utilizar el material para una finalidad comercial y (c) si remezcla, transforma

o crea a partir del material, deberá difundir sus contribuciones bajo la misma licencia que el original.

Resumen de la licencia https://creativecommons.org/licenses/by-nc-sa/4.0/deed.es ES

Texto completo de la licencia https://creativecommons.org/licenses/by-nc-sa/4.0/legalcode 